\section{Use of the lowa Satisfaction with Anesthesia Scale in Portuguese}

Fernandes et al. ${ }^{(1)}$ used the lowa Satisfaction with Anesthesia Scale (ISAS) to measure patient satisfaction after cataract surgery. The ISAS generally is appropriate for cataract surgery and has content validity for monitored anesthesia care ${ }^{(1-3)}$. Fung et al. ${ }^{(4)}$ showed that the ISAS can be used to measure patient satisfaction with cataract care under topical local anesthesia and monitored sedation.

However, the three previous studies that assessed the reliability and validity of ISAS were performed in English. There is a clear distinction in English between the somatic "I felt pain" and the emotive "I hurt." The authors' Methods section does not state that the study was limited to patients who speak and write English at a $4^{\text {th }}$ grade level or higher, as applicable. The authors' Discussion does not mention language. Was the instrument used in English or Portuguese? If Portuguese, what systematic processes were used for translation? What percentage of respondents answered these two questions differently? What was the internal consistency (Cronbach alpha) of the instrument? A Portuguese version of the instrument would be very helpful for future investigations.

In addition, ISAS is copyrighted by Franklin Dexter and the University of lowa Research Foundation. This is stated in each table of the original paper, throughout the second paper, and in each related table of the Fung et al. paper ${ }^{(2-4)}$. Performing a web search with either Google or Bing (performed February 14, 2014) using the term "Iowa Satisfaction with Anesthesia Scale" returned the authorization form for use as the first entry. What steps did the authors follow to use ISAS, and what changes do the authors recommend for the authorization process described at www.FranklinDexter.net/FAQ/FAQ_a32.htm.

Franklin Dexter

Department of Anesthesia, University of lowa, lowa City.

Disclosure of potential conflicts of interest: Please refer to www.FranklinDexter.net/FAQ/FAQ_a1.htm. The lowa Satisfaction with Anesthesia Scale is copyrighted by Franklin Dexter and the University of lowa Research Foundation. Income from the Division's consulting work, including the lowa Satisfaction with Anesthesia Scale scores, is used to fund Division research.

Corresponding author: Franklin Dexter. Division of Management Consulting. Department of Anesthesia University of lowa - 200 Hawkins Dr 6JCP - lowa City, IA 52246 USA. + 1 (319) 621-6360 E-mail: Franklin-Dexter@Ulowa.edu

Submitted for publication: February 17, 2014

Accepted for publication: February 27, 2014

\section{REFERENCES}

1. Fernandes MB, de Souza RV, Vasconcelos GC, Ribeiro KG, Andrade BB, Fernandes CR. Assessing patient satisfaction with cataract surgery under topical anesthesia supplemented by intracameral lidocaine combined with sedation. Arq Bras Oftalmol. 2013; 76(6):345-9.

2. Dexter F, Aker J, Wright WA. Development of a measure of patient satisfaction with monitored anesthesia care: the lowa Satisfaction with Anesthesia Scale. Anesthesiology. 1997;87(4):865-73.

3. Dexter F, Candiotti KA. Multicenter assessment of the lowa Satisfaction with Anesthesia Scale, an instrument that measures patient satisfaction with monitored anesthesia care. Anesth Analg. 2011;113(2):364-8.

4. Fung $D$, Cohen M, Stewart S, Davies A. Can the lowa Satisfaction with Anesthesia Scale be used to measure patient satisfaction with cataract care under topical local anesthesia and monitored sedation at a community hospital? Anesth Analg. 2005;100(6):1637-43.

\section{Reply}

The authors appreciate the thoughtful comments expressed in the letter. Authors have applied published grading system that has been used in the medical field for several situations, including tumor grading, graft rejection grading, heart failure grading (NYHSA score), criteria for diagnosing rheumatological conditions, and many other published guidelines.

We consider the lowa Satisfaction with Anesthesia Scale (ISAS) scale as a very interesting and useful method to measure patient satisfaction after cataract surgery. As stated in letter, ISAS is generally appropriate for cataract surgery. The ISAS had content validity for monitored anesthesia care ${ }^{(1,2)}$ and Fung et al., showed "...ISAS can be used to measure patient satisfaction with cataract care under topical local anesthesia and monitored sedation"(3).

The internal consistency was not measured because this was an exploratory pilot study. All patients were Brazilian and spoke Portuguese. The instrument was applied in Portuguese and our group translated it. All authors speak Portuguese as their native language and English higher than a fourth grade level. The translation was evaluated before its submission by the company American Journal Experts. "I felt pain" was translated exactly as "I felt pain," and "I hurt" was translated as"I hurt." All patients who had answered that they felt pain had answered they did not hurt, and most patients had no pain and had not hurt themselves.

We are glad to know there is interest in validating ISAS in Portuguese. The data obtained herein would be useful for a future pilot study that might examine the reliability and validity of ISAS in Portuguese. Knowing how to best use ISAS would help investigators in future studies.

\section{Manuela Bezerril Cipiao Fernandes}

TSA, Sociedade Brasileira de Anestesia, BA, Hospital Geral de Fortaleza.

Corresponding author: Manuela Fernandes. Department of Anesthesiology. Hospital Geral de Fortaleza. Rua José Vilar, 300/1300 - Fortaleza (CE) - 60125-000 - Brazil.

E-mail: manuelabcf@terra.com.br

\section{REFERENCES}

1. Dexter F, Aker J, Wright WA. Development of a measure of patient satisfaction with monitored anesthesia care: the lowa Satisfaction with Anesthesia Scale. Anesthesiology. 1997;87(4):865-73.

2. Dexter F, Candiotti KA. Multicenter assessment of the lowa Satisfaction with Anesthesia Scale, an instrument that measures patient satisfaction with monitored anesthesia care. Anesth Analg. 2011;113(2):364-8.

3. Fung D, Cohen M, Stewart S, Davies A. Can the lowa Satisfaction with Anesthesia Scale be used to measure patient satisfaction with cataract care under topical local anesthesia and monitored sedation at a community hospital? Anesth Analg. 2005 100(6):1637-43. 